\title{
(6) OPEN ACCESS \\ Adequacy of postgraduate medical training: views of different generations of UK-trained doctors
}

\author{
Fay Smith, Michael J Goldacre, Trevor William Lambert
}

- Additional material is published online only. To view please visit the journal online (http://dx.doi.org/10.1136/ postgradmedj-2016-13456)

UK Medical Careers Research Group, Unit of Health-Care Epidemiology, Nuffield Department of Population Health, University of Oxford Oxford, UK

\section{Correspondence to}

Trevor William Lambert, Nuffield Department of Population Health, UK Medical Careers Research Group, Unit of HealthCare Epidemiology, University of Oxford, Old Road Campus, Oxford OX3 7LF, UK: trevor.lambert@dph.ox.ac.uk

Received 3 October 2016 Revised 23 January 2017 Accepted 6 April 2017 Published Online First 8 May 2017

\section{CrossMark}

To cite: Smith F Goldacre MJ, Lambert TW. Postgrad Med J 2017:93:665-670.

\section{ABSTRACT}

Background Over the last decade, many changes have taken place in the UK, which have affected the training that doctors receive.

Aim To assess doctors' views on quality and adequacy of postgraduate training.

Methods Questionnaires about training sent to UKtrained doctors who graduated between 1974 and 2012. Results Among trainees towards the end of their first year of medical work and training, 36\% agreed that in their first year "Training was of a high standard"; $21 \%$ disagreed; $43 \%$ neither agreed nor disagreed. Only 16\% agreed "I had to perform clinical tasks for which I felt inadequately trained". Among doctors 12 years into their careers, 83\% agreed "My training has been long enough, and good enough, to enable me to practise adequately when I first become/became a consultant or GP". Among senior hospital doctors aged in their 50 s or 60 s, $21 \%$ agreed that "These days, the training of specialist doctors in the NHS is sufficient to enable them to practise adequately when they first become consultants"; $38 \%$ disagreed, and the rest neither agreed nor disagreed. Of senior GPs, $41 \%$ agreed "These days, the training of GP trainees in the NHS is sufficient to enable them to practise adequately when they first become GPs"; 28\% disagreed.

Conclusions Views on early career training were mixed, but few felt exposed to clinical situations beyond their ability. Most newly appointed consultants and GPs felt adequately trained for practice, though many senior doctors were unsure that this was the case.

\section{PURPOSE OF STUDY}

Over the last decade, many changes have taken place in the UK, which have affected the training that doctors receive. The Modernising Medical Careers (MMC) initiative ${ }^{1}$ was implemented in 2005. As part of this training programme, postgraduate doctors complete a 2-year foundation programme consisting of placements in various hospital settings. The scheme is broken down into years F1 and F2. During the F2 year, doctors choose their area of specialism. They can then apply for either 'core' specialist training (ie, a broad training programme in surgery or hospital medicine which can later be narrowed to a particular specialism) or a training programme in a specific specialty. Prior to the introduction of MMC it was common for doctors to take several years to decide on their choice of eventual specialty, during which time the doctor would gain additional broad experience. In parallel, training arrangements and opportunities in clinical practice have been affected by the introduction of the European Working Time Regulation (EWTR), which has restricted the hours that doctors can work to no $>48$ hours a week on average. A review in 2010 of the impact of the EWTR on the training of doctors found that high-quality training 'can be delivered in 48 hours a week' but 'this is precluded when trainees have a major role in out-of-hours service, are poorly supervised and when access to learning is limited'. ${ }^{2}$

In recent years, the General Medical Council (GMC) has evolved from a registration authority to take on a regulatory and advisory role in training. Its 2009 publication Tomorrow's Doctors provided standards of teaching, learning and assessment in UK medical schools for new graduates. ${ }^{3}$ More recently, in 2011, the GMC published The Trainee Doctor, which provided further standards for postgraduate training. ${ }^{4}$

There is some evidence that not all UK doctors rate their training highly. In 2014, 1 in 10 newly qualified UK doctors felt poorly prepared for practice. ${ }^{5}$ In the same year, respondents to the GMC's National Training Survey of doctors in training scored their overall satisfaction with training at 81 points out of 100: foundation doctors tended to give lower scores than those in core training, and senior doctors tended to give the highest scores. ${ }^{6}$

The aim of this article is to assess the views of UK doctors at different stages about the quality of training. It covers results of surveys of doctors at three very different stages in their careers. The first are doctors towards the end of their first year after qualifying; then, doctors about 12 years after qualification who have either completed their postgraduate training or were close to doing so; and finally, very experienced senior doctors aged in their $50 \mathrm{~s}$ or 60s.

\section{STUDY DESIGN}

The UK Medical Careers Research Group undertakes regular multi-purpose surveys of UK-qualified doctors. In this article, we report on questions and statements about training from three different stages after graduation. We grouped these as junior (the graduates of 2008 surveyed in 2009, 2009 in 2010 and 2012 in 2013), middle stage (graduates of 1999 in 2012, 2000 in 2012 and 2002 in 2013) and Senior (graduates of 1974 in 2014 and 1977 in 2014). We sent questionnaires 1 year after qualification (junior), 11-13 years after graduation (middle stage) and 37-40 years after graduation (senior). We sent several reminders to non-respondents. Further details of the methodology are published elsewhere. 
We asked the junior doctors to indicate their level of agreement with the following two statements: "Training was of a high standard" and "I had to perform clinical tasks for which I felt inadequately trained". Doctors could respond using a 3 -point scale covering 'agree', 'neither agree nor disagree' and 'disagree'.

Middle-stage doctors were asked to indicate their level of agreement with the following statement: "My training has been long enough, and good enough, to enable me to practise adequately when I first become/became a consultant or GP" (General Practitioner (GP)). Doctors could respond using a 5 -point scale covering 'strongly agree', 'agree', 'neither agree nor disagree', 'disagree' and 'strongly disagree'. Doctors who disagreed or strongly disagreed with the statement were asked to indicate any of the following areas of training and/or experience in which they felt themselves to be deficient: clinical skills, clinical experience, surgical experience, leadership skills, multi-disciplinary team working, hospital/practice management, life-long learning skills and safety and quality improvement. Doctors could choose more than one area, if more than one applied.

Senior doctors were asked to indicate their level of agreement with the following two statements: "These days, the training of specialist doctors in the NHS is sufficient to enable them to practise adequately when they first become consultants" and "These days, the training of GP trainees in the NHS is sufficient to enable them to practise adequately when they first become GPs". Doctors could respond using a 5-point scale from 'strongly agree' to 'strongly disagree' as above.

We analysed doctors' responses to the questions overall, by cohort and sex and, for the middle-stage and senior doctors, by specialty group. Doctors' descriptions of their specialty of working were grouped by us, for the purpose of this article, into four specialty groups comprising hospital medical specialties, hospital surgical specialties, other hospital specialties combined (paediatrics, emergency medicine, obstetrics and gynaecology, anaesthetics, radiology, clinical oncology, pathology and psychiatry) and general practice. Responses in subgroups were compared statistically using non-parametric tests including $\left(\chi^{2}\right.$, Mann-Whitney and Kruskal-Wallis tests) as appropriate.

\section{RESULTS}

\section{Response rates}

In eight surveys undertaken between 2010 and 2014, we surveyed doctors who graduated between 1974 and 2012. We surveyed 18792 junior doctors, 13087 middle-stage doctors and 5488 senior doctors, a total of 37367 UK doctors from eight different cohorts. The aggregated response rate from contactable doctors, over all eight surveys, was 55.5\% (18 872/34 029; online supplementary appendix 1).

Junior doctors (F1 doctors surveyed in 2009, 2010 and 2013)

Of those who responded, 898 (4.8\%) doctors completed a short version of the questionnaire which did not contain questions about training. These were excluded from the analysis. A further 95 doctors did not answer the question 'Training was of a high standard' and 100 did not answer 'I had to perform clinical tasks for which I felt inadequately trained': these doctors are also excluded from the analysis. Across all junior doctors surveyed in the 3-years of graduation cohorts (2008, 2009 and 2012 graduates), $36 \%$ of the 7734 respondents agreed with the statement 'Training was of a high standard', 43\% neither agreed nor disagreed and 21\% disagreed.

Fifty per cent of respondents who graduated in 2012 agreed with this statement compared with $31 \%$ of 2009 graduates and $28 \%$ of 2008 graduates $\left(\chi_{2}^{2}=311.5, \mathrm{p}<0.001\right)$.

Over the three cohorts, marginally more women than men agreed with this statement $\left(37 \%\right.$ and $\left.34 \% ; \chi_{1}^{2}=4.9, \mathrm{p}<0.05\right)$. Figure 1 illustrates the responses of men and women to this statement in each cohort.

Across all junior doctors who responded, 58\% disagreed with the statement "I had to perform clinical tasks for which I felt inadequately trained", 26\% neither agreed nor disagreed and $16 \%$ agreed. A higher percentage of doctors who had graduated in 2008 than later graduates agreed with this statement: 19\%

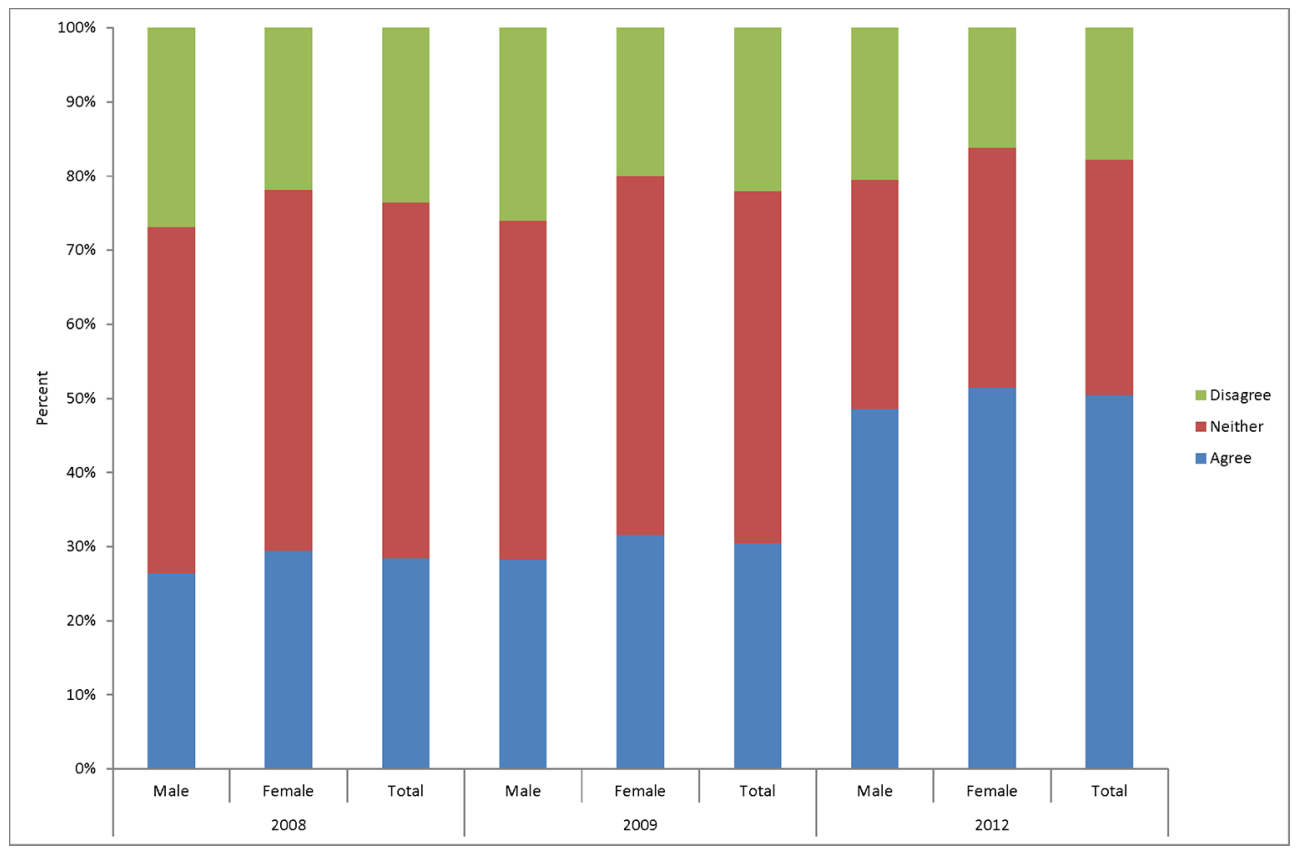

Figure 1 F1 doctors' agreement with the statement 'Training was of a high standard', by sex and cohort. 


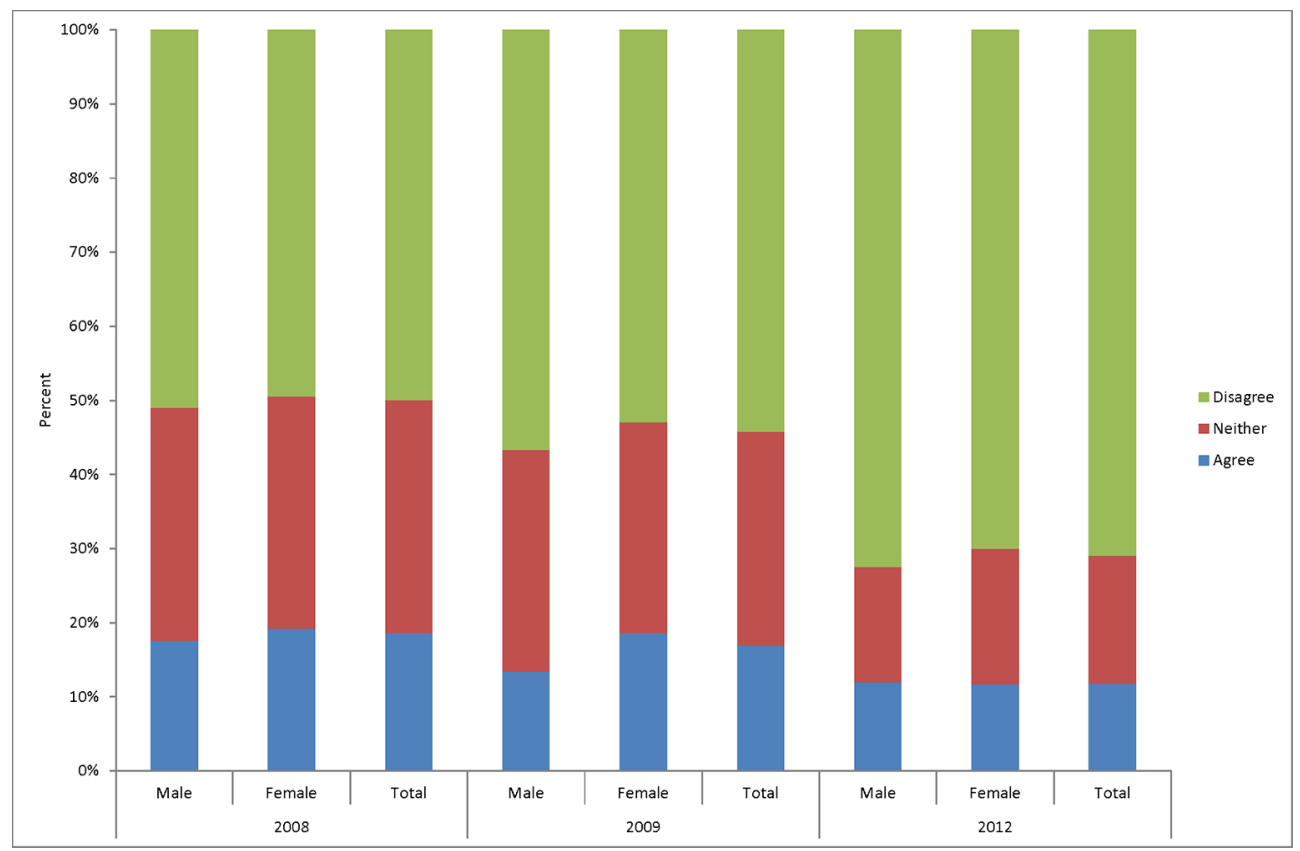

Figure 2 F1 Doctors' agreement with the statement 'I had to perform clinical tasks for which I felt inadequately trained', by sex and cohort.

agreed, compared with $17 \%$ in the 2009 cohort and $12 \%$ in the 2012 cohort $\left(\chi_{2}^{2}=45.7, \mathrm{p}<0.001\right)$. A slightly higher percentage of women than of men agreed with this statement $(17 \%$ and $\left.15 \% ; \chi_{1}^{2}=7.0, \mathrm{p}<0.01\right)$. Figure 2 illustrates the responses of men and women to this statement in each cohort.

\section{Middle-stage doctors (graduates of 1999, 2000 and 2002 surveyed in 2012/2013)}

Across all middle-stage doctors surveyed, 83.0\% strongly agreed or agreed with the statement "My training has been long enough, and good enough, to enable me to practise adequately when I first become/became a consultant or GP” $(24.2 \%$ strongly agreed), 8.6\% neither agreed nor disagreed and $8.4 \%$ disagreed or strongly disagreed (1.0\% strongly disagreed). For convenience, henceforth, we report percentages of agreement and disagreement by combining 'strongly agree' with 'agree' and 'strongly disagree' with 'disagree'. Over the combined surveys, more women than men disagreed with the statement $(9.7 \%$ of women, $6.9 \%$ of men, $\left.\chi_{1}^{2}=14.4, p<0.001\right)$. Graduates of 2002 were slightly more likely to disagree with this statement than other cohorts $\left(\chi_{2}^{2}=9.3, \mathrm{p}<0.010\right.$; figure 3$)$.

When comparing the four specialty groups described in the Study Design section, more surgeons and GPs disagreed with the statement $(9.7 \%$ of surgeons and $11.2 \%$ of GPs, compared

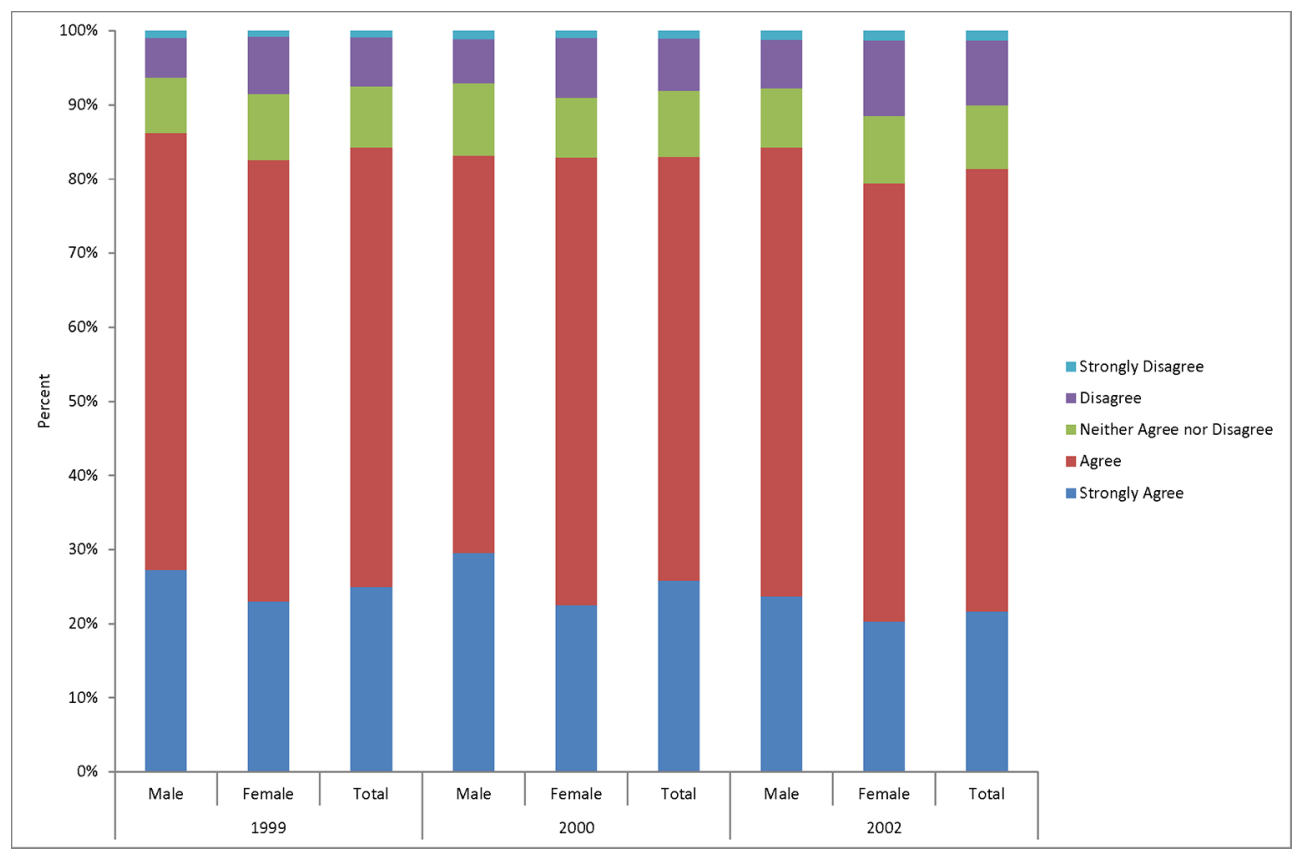

Figure 3 Doctors' agreement with the statement "My training has been long enough, and good enough, to enable me to practise adequately when I first become/became a consultant or GP", by sex and cohort. GP, General Practitioner. 
Table 1 Doctors who felt their level of training on first appointment to a senior post had been deficient in specified areas: percentages (numbers) of all respondents in each specialty group

\begin{tabular}{|c|c|c|c|c|c|}
\hline & $\begin{array}{l}\text { Hospital medical } \\
\text { specialties }(n=1090)\end{array}$ & Surgery $(n=807)$ & Other hospital $(n=2000)$ & GP $(n=2127)$ & All specialties $(n=6024)$ \\
\hline Clinical skills, \% (n) & $2.3(25)$ & $2.1(17)$ & $1.5(30)$ & $3.9(84)$ & $2.6(156)$ \\
\hline Clinical experience, $\%$ ( $\mathrm{n}$ ) & $3.2(35)$ & $2.0(16)$ & $3.2(64)$ & $8.9(189)$ & $5.0(304)$ \\
\hline Surgical experience, $\%$ (n) & $0.7(8)$ & $9.2(74)$ & $1.0(20)$ & $0.6(13)$ & $1.9(115)$ \\
\hline Leadership skills, \% (n) & $3.8(41)$ & $1.4(11)$ & $2.8(56)$ & $6.1(130)$ & $4.0(238)$ \\
\hline $\begin{array}{l}\text { Multi-disciplinary team } \\
\text { working, \% (n) }\end{array}$ & $0.2(2)$ & $1.0(8)$ & $0.6(11)$ & $0.8(17)$ & $0.6(38)$ \\
\hline $\begin{array}{l}\text { Hospital/practice } \\
\text { management, \% (n) }\end{array}$ & $3.5(38)$ & $3.0(24)$ & $2.9(57)$ & $4.8(103)$ & $3.7(222)$ \\
\hline Life-long learning skills, \% (n) & $1.0(11)$ & $1.0(8)$ & $0.7(14)$ & $2.1(44)$ & $1.3(77)$ \\
\hline $\begin{array}{l}\text { Safety and quality } \\
\text { improvement, \% (n) }\end{array}$ & $1.9(21)$ & $1.1(9)$ & $1.6(31)$ & $1.9(41)$ & $1.7(102)$ \\
\hline
\end{tabular}

The table shows only those middle-stage doctors who disagreed or strongly disagreed with the statement "My training has been long enough, and good enough, to enable me to practise adequately when I first become/became a consultant or GP".

GP, General Practitioner.

with $7.0 \%$ for doctors in hospital medical specialties and $5.6 \%$ for doctors in other hospital specialties $\left(\chi_{3}^{2}=48.1, \mathrm{p}<0.001\right.$; online supplementary appendix 2).

Of the 526 doctors who disagreed or strongly disagreed with this statement, 514 nominated one or more areas in which they felt their level of training on first appointment to a senior post had been deficient (table 1).

Clinical experience, leadership skills and management skills were the areas in which the largest number felt deficient. Comparing specialties, there were significant differences in feeling deficient in four areas: surgical experience $(9.2 \%$ of surgeons compared with $0.6 \%-1.0 \%$ for the other groups), clinical experience $(8.9 \%$ of GPs compared with $2.0 \%-3.2 \%$ for the other groups), leadership skills (6.1\% of GPs compared with $1.4 \%-3.8 \%$ for the other groups) and clinical skills (3.9\% of GPs compared with $1.5 \%-2.3 \%$ for the other groups $)\left(\chi_{3}^{2}=263.2\right.$, 103.1, 47.5 and 26.1, respectively, all $\mathrm{p}<0.001)$. Counts and percentages within the individual specialties comprising the 'other hospital' group were small, and the variability between specialties was unremarkable, with one exception: 18 of the 20 doctors who felt their surgical experience was deficient (table 2) were in obstetrics and gynaecology, and these represented $18 \%(18 / 99)$ of all respondents in obstetrics and gynaecology. Comparing men and women, there were significant differences in feeling deficient in two areas: clinical experience (men 3.6\%, women $6.2 \%$ ) and leadership skills (men 3.0\%, women $4.8 \%$ ) $\left(\chi_{1}^{2}=21.3\right.$ and 12.3 , respectively, both $\left.\mathrm{p}<0.001\right)$. There were no significant cohort differences.

\section{Senior doctors (graduates of 1974 and 1977 surveyed in 2014)}

Of those who responded, 98 (1.8\%) doctors completed a short version of the questionnaire, which did not contain questions about training. These were excluded from the analysis, leaving data from 3600 respondents.

Combining data from the two cohorts, 24.9\% strongly agreed or agreed with the statement "These days, the training of GP trainees in the NHS is sufficient to enable them to practise adequately when they first become GPs", 16.1\% neither agreed nor disagreed and $24.3 \%$ disagreed or strongly disagreed (table 2). Of those currently working in general practice, agreement was higher (40.7\% strongly agreed or agreed), though $28.4 \%$ disagreed or strongly disagreed. No difference was observed between men and women doctors, or between the cohorts.

Across all senior doctors surveyed, 15.9\% strongly agreed or agreed with the statement "These days, the training of specialist doctors in the NHS is sufficient to enable them to practise adequately when they first become consultants", $16.6 \%$ neither agreed nor disagreed and $32.4 \%$ disagreed or strongly disagreed. Considering only the replies of those currently working in

Table 2 Doctors who agreed or disagreed with statements about the adequacy of training of junior and middle stage doctors 'these days' — views of senior doctors (graduates of 1974 and 1977) surveyed in 2014

\begin{tabular}{|c|c|c|c|c|c|c|c|c|}
\hline $\begin{array}{l}\text { Training is } \\
\text { sufficient }\end{array}$ & & $\mathrm{N}(100 \%)$ & $\begin{array}{l}\text { Strongly } \\
\text { agree (\%) }\end{array}$ & Agree (\%) & $\begin{array}{l}\text { Neither agree } \\
\text { nor disagree }(\%)\end{array}$ & Disagree (\%) & $\begin{array}{l}\text { Strongly } \\
\text { disagree (\%) }\end{array}$ & $\begin{array}{l}\text { Don't know/no } \\
\text { reply (\%) }\end{array}$ \\
\hline \multirow[t]{3}{*}{ GP training * } & All respondents & 3600 & 2.9 & 22.0 & 16.1 & 16.7 & 7.6 & 34.6 \\
\hline & In clinical practicet & 1043 & 2.9 & 20.0 & 15.7 & 14.1 & 8.8 & 38.4 \\
\hline & In GP & 384 & 5.5 & 35.2 & 12.0 & 19.0 & 9.4 & 19.0 \\
\hline \multirow[t]{3}{*}{ Hospital training } & All respondents & 3600 & 1.3 & 14.6 & 16.6 & 22.9 & 9.5 & 35.1 \\
\hline & In clinical practicet & 1043 & 1.4 & 14.0 & 17.8 & 21.3 & 11.1 & 34.3 \\
\hline & In hospital medicine & 174 & 1.1 & 20.1 & 14.9 & 28.2 & 9.8 & 25.9 \\
\hline
\end{tabular}

*These days, the training of GP trainees in the NHS is sufficient to enable them to practise adequately when they first become GPs.

tExcludes those doctors who are not working in clinical practice or who have retired.

¥These days, the training of specialist doctors in the NHS is sufficient to enable them to practise adequately when they first become consultants.

GP, General Practitioner. 
hospital medicine (ie, whether in surgery, hospital medicine or other hospital-based specialties), agreement was slightly higher (21.2\% agreed), but $38.0 \%$ disagreed or strongly disagreed. No difference was observed between men and women doctors or between the 1974 and 1977 cohorts.

\section{DISCUSSION \\ Main findings}

Junior doctors were polarised in their opinion of whether the training they had received was of a high standard. A fifth of doctors disagreed that their training had been of a high standard; and just under two-fifths agreed. The most recent graduates (those who graduated in 2012) were more satisfied with their training than their predecessors. More women than men agreed that their training had been of a high standard. Only a small minority reported that they had to perform clinical tasks for which they felt inadequately trained. In this respect, the most recent graduation cohort felt better trained than its predecessors, as did women compared with men.

Most middle-stage doctors agreed that their training had been long enough, and good enough, to enable them to practise adequately when they first qualified as a consultant or GP. A higher percentage of women than men felt that their training had not been long enough. A higher percentage of surgeons and GPs, compared with other specialty groups, felt that their training had not been long enough. Doctors who were dissatisfied with their training identified clinical experience, leadership skills and management skills as areas of deficiency.

Senior GPs were polarised in their opinion of whether the training of GP trainees in the NHS is sufficient to enable them to practise adequately when they first become GPs. Half of GPs agreed, but one-third disagreed. Senior hospital doctors were more negative about the training of specialist doctors in the NHS: just over half disagreed that the training is sufficient to enable doctors to practise adequately when they first become consultants.

\section{STRENGTHS AND LIMITATIONS}

The study has limitations. Although the response rate of this study was high for surveys of this type, non-responder bias is a possibility. We acknowledge that the study is reporting doctors' self-assessment of the quality of training. In terms of a Kirkpatrick learning evaluation model, ${ }^{8}$ it is restricted to a level 1 evaluation-in other words, we report what the doctors thought and felt about their training and not any formal evaluation of the quality of the training as a learning experience. The self-reports of the junior doctors cover their experience as it currently was at the time of reply. The self-reports of the middle-stage doctors refer to their time of first appointment to a senior hospital or GP post. For some, especially those in hospital practice, this may have been reasonably contemporary; for others, the replies are based on recollection of how they felt a few years earlier and may be limited by the passage of time. The responses of the senior doctors were about their current impression of the adequacy of training of newly appointed senior doctors.

The study's strengths include the use of a unique national data set. Question wordings and response options were consistent over time, enhancing the comparability of results. We believe that, because we are an independent research group unaligned to employers, trainers or regulators, our respondents provide honest answers without any concerns about possible repercussions of doing so.

\section{Comparison with the existing literature}

We found that a fifth of junior doctors disagreed that their training had been of a high standard. This finding concurs with the results from a survey in 2014 which found that 10\% of junior doctors felt poorly prepared for practice. ${ }^{5}$ Another UK study found that one-quarter of foundation doctors who graduated in 2011 were pathologically anxious. ${ }^{9}$

We found that two-fifths of junior doctors agreed that their training had been of a high standard. This figure is lower than the four-fifths of doctors who were satisfied with their training according to the GMC's National Training Survey of 2014, although the difference may, in part, reflect variations in question wording.

Our study found that some surgeons and GPs, who graduated between 1999 and 2002, felt that their training had not been long enough or good enough. These doctors would have started their postgraduate training between 2004 and 2007, at the time when the EWTR was being implemented. A review of the impact of the EWTR found that specialties (such as surgery) with 'high emergency and out of hours workloads' perceived EWTR to have had a negative impact. ${ }^{2}$ This report also recognised that GPs in training face 'the same challenges as other trainees when rotating through hospital-based specialties'.

We identified clinical experience, leadership skills and management skills as areas of potential deficiency. Similarly, a study of doctors in training (up to those in year 3 of specialist training) found that $89 \%$ of doctors want to be effective leaders, and that doctors who have attended leadership training have a greater desire and perceived ability to help improve the NHS.

\section{CONCLUSION}

Juniors' views on the quality of their training remain mixed, although the position is improving for the most recent graduates and the percentages reporting that they have been required to do clinical work for which they feel inadequately trained is small and falling. A minority of doctors who had completed their training did not feel fully adequate in areas such as clinical experience or

\section{Main messages}

Recent UK medical graduates hold a more positive view of the quality of their training in their first postqualification year than did their predecessors; and percentages reporting being required to undertake tasks for which they felt inadequately trained have fallen substantially.

- Middle-stage doctors, who had either completed their postgraduate training or were close to doing so, had a high level of confidence that they were ready for independent practice as consultants and general practitioners (GPs).

- Senior doctors held mixed views about whether newly appointed consultants and GPs really were adequately trained for independent practice.

\section{Current research questions}

- Is the level of clinical experience really lower for a newly qualified consultant or GP in the UK than it was years ago?

- Are senior doctors correct to have this view, or is there an element of generational bias in their responses?

- If experience is deficient, how should training be adapted to improve? 
leadership skills. Of senior doctors, about a quarter and a third specified, respectively, that newly appointed GPs and hospital doctors are not yet adequately experienced for the job. It is for educators to consider whether any adverse effects of recent changes to postgraduate training programmes can be mitigated by further changes to educational delivery.

Acknowledgements The authors thank Janet Justice and Alison Stockford for data entry. They are very grateful to all the doctors who participated in the surveys.

Contributors TWL and MJG: designed and conducted the surveys. FS and TWL: designed the analysis. FS: performed the analysis and wrote the first draft of the paper. All authors contributed to further drafts and approved the final version.

Funding This is an independent report commissioned and funded by the Policy Research Programme in the Department of Health (project number 016/0118). The views expressed are not necessarily those of the funding bodies.

Competing interests All authors have completed the Unified Competing Interest form at www.icmje.org/coi_disclosure.pdf (available on request from the corresponding author) and all authors want to declare: (1) financial support for the submitted work from the policy research programme, Department of Health. All authors also declare; (2) no financial relationships with commercial entities that might have an interest in the submitted work; (3) no spouses, partners or children with relationships with commercial entities that might have an interest in the submitted work; (4) no non-financial interests that may be relevant to the submitted work.

Ethics approval National Research Ethics Service, following referral to the Brighton and Mid-Sussex Research Ethics Committee in its role as a multi-centre research ethics committee (ref 04/Q1907/48 amendment Am02 March 2015).

Provenance and peer review Not commissioned; externally peer reviewed.

Data sharing statement The authors may be available to provide aggregated data on which the analysis is based, on request. It may be possible for the authors to make tabulated data, produced in the course of this work but not included in the paper, available to interested readers on request.

Open Access This is an Open Access article distributed in accordance with the Creative Commons Attribution Non Commercial (CC BY-NC 4.0) license, which permits others to distribute, remix, adapt, build upon this work non-commercially, and license their derivative works on different terms, provided the original work is properly cited and the use is non-commercial. See: http://creativecommons.org/ licenses/by-nc/4.0/

(C) Article author(s) (or their employer(s) unless otherwise stated in the text of the article) 2017. All rights reserved. No commercial use is permitted unless otherwise expressly granted.

\section{REFERENCES}

1 Department of Health. Modernising medical careers. The next steps: the future shape of foundation, specialist and general practice training programmes. London: Department of Health, 2004.

2 Temple J. Time for training. A review of the impact of the European working time directive on the quality of training. London: Medical Education England, 2010.

3 General Medical Council. Tomorrow's Doctors. London: General Medical Council, 2009.

4 General Medical Council. The trainee doctor. London: General Medical Council, 2011.

5 General Medical Council. Be prepared: are new doctors safe to practise? London: General Medical Council, 2014.

6 General Medical Council. National training survey 2014: key findings. London: General Medical Council, 2014.

7 Goldacre MJ, Lambert TW. Participation in medicine by graduates of medical schools in the United Kingdom up to 25 years post graduation: National cohort surveys. Acad Med 2013;88:699-709.

8 Smidt A, Balandin S, Sigafoos J, et al. The Kirkpatrick model: a useful tool for evaluating training outcomes. J Intellect Dev Disabil 2009;34:266-74.

9 Van Hamel C, Jenner LE. Prepared for practice? a national survey of UK foundation doctors and their supervisors. Med Teach 2015;37:181-8. 